Abstract P0-0771 Table 1

\begin{tabular}{|c|c|c|c|c|c|c|}
\hline & \multicolumn{3}{|c|}{ Before surfactant trea tment } & \multicolumn{3}{|c|}{ After surfactant treatment } \\
\hline & $\begin{array}{l}\text { Compliance } \\
\mathrm{mV} / \mathrm{cm} / \mathrm{H}_{2} \mathrm{O} / \mathrm{kg}\end{array}$ & $\begin{array}{l}\text { Resistance } \\
\mathrm{cm} / \mathrm{H}_{2} \mathrm{O} / \mathrm{L} / \mathrm{sn}\end{array}$ & $\mathrm{C}_{20} / \mathrm{C}$ & $\begin{array}{l}\text { Compliance } \\
\mathrm{m} / \mathrm{cm} / \mathrm{H}_{2} \mathrm{O} / \mathrm{kg}\end{array}$ & $\begin{array}{l}\text { Resistance } \\
\mathrm{cm} / \mathrm{H}_{2} \mathrm{O} / \mathrm{L} / \mathrm{sn}\end{array}$ & $\mathrm{C}_{20} / \mathrm{C}$ \\
\hline $\begin{array}{l}\text { Beractant } \\
\mathrm{n}=5\end{array}$ & $0,28 \pm 0,13$ & $483 \pm 101$ & $1,3 \pm 1,2$ & $1,33 \pm 1.1$ & $322 \pm 107$ & $1,19 \pm 1$ \\
\hline $\begin{array}{l}\text { Poractant } \\
\text { alfa } \\
\mathrm{n}=5\end{array}$ & $0,35 \pm 0,17$ & $498 \pm 210$ & $2,8 \pm 1,7$ & $0,5 \pm 0,29$ & $432 \pm 165$ & $2,6 \pm 0,87$ \\
\hline
\end{tabular}

relationship between initial lung mechanics and occurrence of bronchopulmonary dysplasia (BPD).

Method Preterm infants who were

Results 10 premature infants were studied. Mean gestational age was $28.4 \pm 1.6(26-31)$ weeks and mean birth weight was 955 $\pm 155(710-1250)$ g. Five infants received beractant and the other five received poractantalpha. The alteration of lung mechanics after surfactant administration was summarized in Table 1.

Conclusion Surfactant therapy significantly reduced the resistance and improved the lung compliance. These effects were not directly related to the type of surfactant administered.

\section{PO-0772 EFFECTS OF CAFFEINE THERAPY ON RESPIRATORY MORBIDITIES IN VERY LOW BIRTH WEIGHT INFANTS}

F Yavanoglu Atay, D Bidev, O Bozkurt, G Kutman, FE Canpolat, SUNA Oguz, N Uras, U Dilmen. Neonatology, Zekai Tahir Burak Women Health Care Education and Research Hospital, Ankara, Turkey

\subsection{6/archdischild-2014-307384.1411}

Introduction and aim Previous studies demonstrated that caffeine seems to be effective for reducing the risk of bronchopulmonary dysplasia and for decreasing the need for reintubation. We aimed to evaluate the effects of caffeine therapy on respiratory morbidities in very low birth weights infants.

Method We aimed to review patient records for a 5 year period (2008-2013) retrospectively. Infants whose birth weight $<1250$ gr and gestational age $<32$ weeks were studied. Data collected for analysis included patient demographics, respiratory morbidities and mortality.

Results A total of 290 patient records were analysed, of them 148 infants were treated with caffeine $(\mathrm{CT}+), 142$ infant did not receive caffeine therapy (CT-). Gestational ages (27.9 \pm 2 vs $27.7 \pm 2.7$ weeks) and birth weights (967 \pm 186 vs $980 \pm 196$ g) were similar between groups $(\mathrm{p}>0.05)$. Basic characteristics and risk factors were similar between groups. CPAP failure was significantly lower in CT + group $(25,4 \%$ vs $41.1 \%, p=0.02)$ Oxygen requirement on 36 weeks $(13.2 \%$ vs $7.4 \%$ in CT + and CT- groups respectively) were similar between groups ( $\mathrm{p}>0.05)$. Mortality rate $(18.9 \%$ vs $54 \%)$, BPD or death $(28.6 \%$ vs $57 \%)$ and duration of mechanical ventilation $(2.9 \pm 5$ vs $4.8 \pm 7.7$ days) were significantly lower in CT + group $(p<0.01)$.

Conclusion We demonstrated that caffeine therapy significantly reduced the mortality rate, death or BPD and CPAP failure VLBW infant yet no significant difference was observed on therates of BPD. This is an ongoing study and maybe the final analysis will yield different results.

\section{P0-0773 LUNG ULTRASOUND FINDINGS IN CONGENITAL LUNG MALFORMATIONS}

${ }^{1} \mathrm{~N}$ Yousef, ${ }^{1} \mathrm{M}$ Mokhtari, ${ }^{2} \mathrm{~S}$ Franchi-Abella, ${ }^{1} \mathrm{P}$ Tissieres, ${ }^{3} \mathrm{D}$ De Luca. ${ }^{1}$ Neonatal and Pediatric Intensive Care Unit - FAME Dept, South Paris University Hospitals - Bicêtre Medical Centre, Paris, France, ${ }^{2}$ Department of Pediatric Radiology, South Paris University Hospitals - Bicêtre Medical Centre, Paris, France; ${ }^{3}$ Division of Pediatrics and Neonatal Critical Care - FAME Dept, South Paris University Hospitals "A. Beclère" Medical Center, Paris, France

\subsection{6/archdischild-2014-307384.1412}

Background and aims Congenital cystic adenomatoid malformation (CCAM) is a group of rare congenital malformations of the lung and airways, with varying clinical pictures. Lung ultrasound (LUS) is a quick, easy and cheap imaging technique that is increasingly used in critical care settings. Specific LUS findings have been described for some types of neonatal lung injury, but no formal data exist on pulmonary malformations. We here describe ultrasound findings in CCAM.

Methods Three patients with a prenatal diagnosis of CCAM and presenting with neonatal respiratory distress were examined by LUS, during the first week of life, using a linear $12-18 \mathrm{MHz}$, or a microconvex 7,5 MHz probe. Chest CT-scans were used as reference.

Results LUS findings were variable and corresponded well with CT-scan images (LUS dynamic video recordings will be showarn). One patient had a single large hypoechogenic cystic lesion. Two patients had several hypoechogenic lesions, of various size and form, surrounded by consolidated lung tissue. All patients showed normal lung patterns in the areas adjacent to the CCAM. LUS did not permit the exact localization of lung lesions.
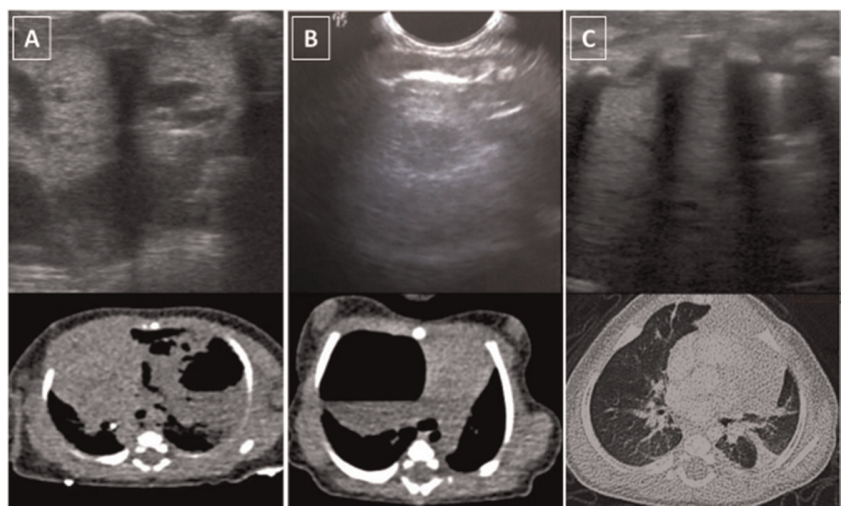

Abstract P0-0773 Figure 1

Conclusions We provide the first formal description of LUS findings in neonates with CCAM. Further studies are necessary to define the place of LUS in the management of CCAM. LUS could be a useful tool in screening asymptomatic patients and determining optimal timing for CT-scan and surgery, thereby limiting radiation exposure.

\section{PO-0774 LUNG ULTRASOUND FINDINGS IN MECONIUM ASPIRATION SYNDROME}

${ }^{1} \mathrm{~N}$ Yousef, ${ }^{2} \mathrm{M}$ Piastra, ${ }^{3} \mathrm{R}$ Brat, ${ }^{4} \mathrm{P}$ Manzoni, ${ }^{1} \mathrm{M}$ Mokhtari, ${ }^{1} \mathrm{P}$ Tissieres, ${ }^{3} \mathrm{D}$ De Luca. ${ }^{1}$ Neonatal and Pediatric Intensive Care Unit - FAME Department, South Paris University Hospitals - Bicêtre Medical Centre, Paris, France; ${ }^{2}$ Pediatric Intensive Care Unit Institute of Anesthesiology and Critical Care, University Hospital "A. Gemelli" - Catholic University of the Sacred Heart, Rome, Italy; ${ }^{3}$ Division of Pediatrics and Neonatal Critical Care - FAME Department, South Paris University Hospitals - "A. Beclère" Medical Center, Paris, France; ${ }^{4}$ Neonatal Intensive Care Unit, OISRM S. Anna, Turin, Italy

10.1136/archdischild-2014-307384.1413 

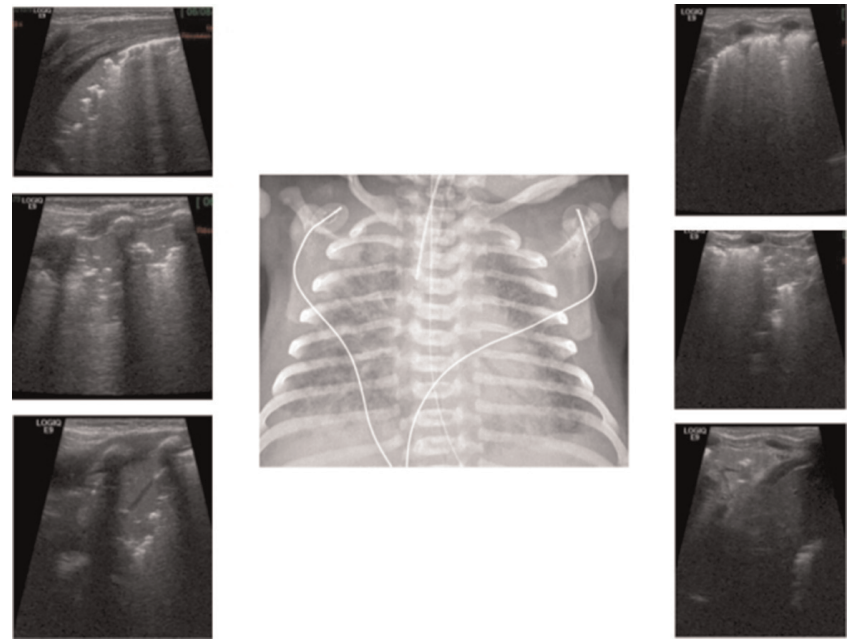

\section{Abstract P0-0774 Figure 1}

Background and aims Meconium aspiration syndrome (MAS) is a rare and life-threatening neonatal lung injury induced by meconium in the lung and airways. Lung ultrasound (LUS) is a quick, easy and cheap imaging technique that is increasingly used in critical care settings. Specific LUS findings have been described for some types of neonatal lung injury, but no formal data exists on ultrasound imaging of MAS. We here describe ultrasound findings in MAS.

Methods Five patients with MAS of variable severity were examined by LUS during the first hours of life, using either a microconvex $7,5 \mathrm{MHz}$, or a linear $12-18 \mathrm{MHz}$ probe. Chest Xrays were used as reference.

Results A range of unevenly distributed dynamic signs was observed in five neonates with MAS (LUS dynamic video recordings will be shown). The following signs were seen in all cases: 1) B-pattern (interstitial) coalescent or sparse; 2) consolidations; 3) atelectasis; 4) bronchograms. No pattern was observed for distribution of signs in lung areas. The signs in the same lung area varied with time, reflecting the changing auscultation patterns. In our opinion, this is due to the changing localisation of meconium and the displacement or dissolution of meconium plugs. LUS images corresponded well with X-ray findings.

Conclusions We provide the first formal description of LUS findings in neonates with MAS. LUS seems to be a useful and promising tool in the diagnosis and management of MAS, providing real-time bedside imaging, with the additional potential benefit of limiting radiation exposure in sick neonates.

\section{PO-0775 RESPIRATORY MORBIDITIES IN VERY LOW BIRTH WEIGHT INFANTS IN A TERTIARY LEVEL HOSPITAL, SAUDI ARABIA}

Z Al-Salam, M Abdelbaky, A Ammari, FT Kashlan, M Alshaar, A Abdelrahim, F Quraishi. Neonatal Medicine-Pediatrics, Prince Sultan Military Medical City, Riyadh, Saudi Arabia

\subsection{6/archdischild-2014-307384.1414}

Background and aims The improvement of perinatal care has led to significant reduction in perinatal mortality. In our region, there is limited data about prematurity-related outcomes. Therefore, we designed this study to report the in-hospital respiratory morbidities and interventions in VLBWI.

Methods This is a retrospective study of all inborns (Prince Sultan Military Medical City (2004-2012), Riyadh-Saudi Arabia) with a birth weight (b.wt) of $<1500 \mathrm{~g}$ and gestational age (GA)
$<34$ wks, with no major anomaly. In-hospital respiratory morbidities and interventions were reported. Chronic lung disease (CLD) was defined as requirement of $\mathrm{O}_{2}$ at 36 wks postconception.

Results 1262 were included (GA: $28 \pm 3$ wks, b.wt: $1016 \pm$ $298 \mathrm{~g}$, median length of stay (IQR) was 48d (30-74), survival: $83 \%$ and exposure to any antenatal steroid: 79\%). Respiratory distress syndrome (RDS), CLD and pneumothorax were diagnosed in 87, 16.3 and 5.9\%, respectively. Surfactant, indomethacin and post-natal dexamethasone were used in 67, 23 and 7\%, respectively. Surgical ligation of PDA was required in $3 \%$ and iNO was used in $9 \%$. The median days on mechanical ventilation, CPAP and $\mathrm{O}_{2}$ were 2 (0-14),5 (1-21) and 6 (1-36). Males were more likely to have worse RDS, pulmonary haemorrhage and also required longer days on $\mathrm{O}_{2}$ and received more surfactant (all p < 0.05).

Conclusions The findings of this study suggest that our population is comparable to that reported in the literature and males are at higher risk. These data would set a baseline for further clinical trials and quality improvement projects in our region.

\section{PO-0776 WITHDRAWN}

\section{Nephrology}

\section{PO-0777 THE BARTTER SYNDROME IN CHILDREN}

M Amiryan, M Nikitina, I Leviashvili. Pediatric Nephrology, Saint-Petersburg State Pediatric Medical University, Saint-Petersburg, Russia

\subsection{6/archdischild-2014-307384.1415}

Abstract Bartter syndrome (BS) tubulopathy with autosomal recessive (AR) type of genetic inheritance, manifested hypokalemia, metabolic alkalosis, hyperreninemia, hyperplasia juxtaglomerular apparatus (JGA), hyperaldosteronism, in some patients, hypomagnesemia. Classification: primary, congenital, genetically based, secondary in the structure of other family kidney disease. Objective Explore catamnesis of 5 children to identify the course and treatment of BS.

Methods Catamnestic, clinical and laboratory, molecular genetic methods.

Results Of the 5 patients observed in 3 diagnosed primary, genetically determined BS, have 2 secondary BS. Main manifestations of BS with neonatal age: vomiting, diarrhoea, polyuria, polydipsia, signs of dehydration, with infants: hypocalcemic convulsions, paresis hypokalemic. In 3 children with AR Bartter syndrome aged 1-5 years observed: polyuria, polydipsia, growth retardation and psychomotor development, uncompensated metabolic alkalosis, hypochloremia, hypocalcemia, hyponatremia, acidaminuria, increased excretion of $\mathrm{K}, \mathrm{Na}, \mathrm{Cl}$ in urine, nephrocalcinosis, calciuria, hypokalemia (from 2.2-3.3 mmol/l), hyperprostaglandin-E-emia. Genetic testing of 1 type BS found a replacement gene with $3287 \mathrm{C}>\mathrm{T}(\mathrm{r}$. Thr1096 IIe) in the heterozygous state. Children with secondary forms, aged 3-11 years, BS manifested on the background of pheochromocytoma without dysfunction the decrease in glomerular filtration rate. In a result of therapy with indomethacin, drugs potassium all patients had elevated potassium in serum, corrected metabolic alkalosis.

Conclusions Bartter syndrome - is a rare tubulopathy. The necessary therapy with nonsteroidal anti-inflammatory drugs (indometacin, celecoxib) drugs potassium prevents the development of complications. 